\title{
A Angústia do Formato: uma História dos Formatos Fonográficos
}

\author{
Leonardo De Marchi ${ }^{1}$ \\ Universidade Federal Fluminense \\ leonardodemarchi@globo.com
}

\begin{abstract}
Resumo: No presente texto, analisa-se a formação da indústria fonográfica utilizando como referencial a história dos suportes sonoros para música. A hipótese é que os diferentes meios de comunicação que transportam a informação sonora revelam aspectos importantes das relações da indústria fonográfica com outros ramos da comunicação. O objetivo é entender quais são os efeitos de diferentes tecnologias da comunicação no desenvolvimento da fonografia, dos primórdios à era digital.
\end{abstract}

Abstract: In this essay, the proposition is to understand the formation of the phongraphic industry by analysing the history of its Technologies, in particular, the phonographic formats. The hypothesis is that the development of the media in which sound is recorded reveals important aspects of the conections between different sectors of the communication industries. In another words, the goal is to undestand the effetcs of the materiality of Technologies of communication in the configuration of phonography, from early times to the digital era.

Resumén: En este texto, la história de los soportes sonoros es utilizada para analizar la formación de la indústria fonográfica. La hipótesis es que los diversos medios que llevan la información sonora presentan importantes aspectos de las relaciones de la industria fonográfica com los otros sectores de comunicación. Lo objetivo es compreender quales son los efectos de las diversas tecnologias de comunicación en el desarrollo de la fonografia, de los primódios hasta la era digital.

Palavras-Chave: suporte sonoro; indústria fonográfica; tecnologia da comunicação.

\footnotetext{
${ }^{1}$ Mestrando do Programa de Pós-Graduação em Comunicação da Universidade Federal Fluminense (UFF), onde desenvolve uma pesquisa sobre indústria fonográfica independente e novas tecnologias da comunicação. Bacharel em Jornalismo pela mesma universidade, foi bolsista de iniciação científica (CNPq/Pibic, 2002-2004) da pesquisa "Música Eletrônica, Tecnologias da Comunicação \& Dinâmicas Identitárias”.
} 


\section{Introdução}

Em sua coluna de opinião no jornal O Globo, Arthur Dapieve descreveu com propriedade um costume dos aficionados por música gravada. Sob o título “A Angústia do Formato: não é nada disso que vocês estão pensando", observou que

Conforme os suportes para áudio foram mudando, do LP para o CD, sem falar na experiência extraconjugal com o MP3, os fãs se viram obrigados a adquirir uma nova versão "bombada" do disco que já possuíam num formato "ultrapassado". (...). Não há um fim nesse processo, (...). Enquanto existirem pessoas, ouvidos, arte, vida, os terráqueos continuarão a comprar novas versões do "Álbum Branco", dos Beatles. É o que chamo aqui de angústia do formato. Nada é definitivo: todos, ouvintes e suportes sonoros, encontram-se sempre na iminência de passar deste para melhor. (jornal, $O$ Globo, o8 de outubro de 2004)

Em outras palavras, a “angústia do formato” é o contínuo consumo de um mesmo conteúdo em diferentes tecnologias da informação. Com efeito, o colunista toca num ponto central da cultura fonográfica, os suportes sonoros. Como Dapieve sinaliza, estes são relevantes não apenas pelo que contêm, mas por afetarem diretamente a forma como experimentamos os conteúdos. De fato, eles influenciam técnicas de audição, estéticas musicais e apontam para uma história da Indústria Cultural, uma vez que seu desenvolvimento reflete dinâmicas de mercado que aproximam diversos setores da comunicação.

No presente trabalho, analisa-se a história dos suportes de reprodução sonora com o intuito de compreender como a indústria fonográfica foi se transformando num importante setor da comunicação. Acredita-se que o desenvolvimento da materialidade das tecnologias de informação sonora ${ }^{2}$ do cilindro ao $\mathrm{MP}_{3}$ - revela dinâmicas estruturais maiores, possibilitando uma visão geral da fonografia. Em suma, quer-se entender quais são os efeitos de diferentes tecnologias da comunicação no desenvolvimento da indústria fonográfica.

\footnotetext{
2 De fato, neste texto não há menção a todos os suportes sonoros que já existiram. Privilegiaram-se os formatos que historicamente foram mais importantes para o desenvolvimento da indústria fonográfica internacional.
} 


\section{Tecnologias da Comunicação e Indústria Fonográfica}

Para discutir o tema das tecnologias de reprodução sonora na comunicação, devem-se discriminar três perspectivas referenciais. Assim, a primeira linha de análise está ligada à Escola de Frankfurt, particularmente, ao pessimismo adorniano e à noção de Indústria Cultural. Nesta perspectiva, a valorização da técnica, fruto da instrumentalização da razão, e a transformação da cultura em mercadoria de consumo massivo implicam na deteriorização do conteúdo. Numa sociedade que apreende a cultura enquanto mercadoria, a relação entre meio e conteúdo é de perda para este (Adorno \& Horkheimer, 2002; Dias, 2000). Outra importante abordagem baseia-se na tradição da "construção social” da tecnologia. Nesta vertente, estuda-se o processo pelo qual um produto (tecnologia) e sua apropriação cultural (uso) contribuem para a significância social do objeto. Dessa forma, analisam como os atores sócio-econômicos discutem e estabelecem a forma como ele é pensado, produzido e consumido. Aqui, a tecnologia é tomada como dado $a$ priori ou secundário da análise, pois o objetivo é compreender como se constrói socialmente um produto cultural (Dowd, 2002; Gitelman, 1999; Keightley, 2004; Sterne, 2003).

A terceira perspectiva abarca, na verdade, uma série de estudos que comungam o interesse pelos efeitos da materialidade dos suportes da comunicação na cultura3 ${ }^{3}$ Dentre as diversas contribuições, destaca-se o conjunto de pensadores agregados sob o rótulo de "Escola de Toronto". Especificamente, ao trabalharmos com a história 4 dos meios, remetemo-nos a dois autores: Harold Innis e Marshall McLuhan5.

\footnotetext{
3 Para uma história e análise desses estudos, ver Singer, 2001; Sá, 2004.

4 Os autores da Escola de Toronto trabalham com a noção de evolução das tecnologias. No entanto, acreditamos que a aplicação da teoria de Darwin ao campo das tecnologias representa um ponto de vista problemático, pois diz respeito a uma visão marcadamente anglo-americana da relação natureza, tecnologia e sociedade. Dessa forma, preferimos adotar um termo narrativo como História.

5 Sublinha-se que a seguinte discussão dos autores da chamada Escola de Toronto é resultado dos debates surgidos ao longo do curso Evolução das Novas Tecnologias, ministrado pelo
} 
Innis foi o precursor da abordagem que veio a caracterizar a chamada Escola de Toronto. Economista por formação, seus últimos trabalhos foram marcados pelo estudo da relação entre tecnologias da comunicação e formações políticas. Em seu insight, Innis (1999) percebera que as características físicas dos meios de comunicação exerciam grande influência na formação de determinados sistemas sócio-econômicos. Assim, analisou a história das tecnologias da comunicação, buscando relacionar estas com o surgimento e extinção de governos ${ }^{6}$. Ainda que suas categorias trouxessem problemas empíricos, seus ensaios (considerados "pensamentos em construção" por simpatizantes e críticos) contribuíram decisivamente para a consideração das características materiais das tecnologias da comunicação como elementos relevantes na análise cultural7.

O que nos interessa em Marshall McLuhan é, neste texto, o que ele “estende” da análise de Innis. Assim, destacam-se dois significados que a palavra "meio"8 adquire em sua obra. O primeiro é o entendimento de uma dinâmica tecnológica contida na frase o conteúdo de um meio é outro meio. Nela, o autor estava se referindo à percepção de que uma nova tecnologia se apropria da forma de sua antecessora para construir uma significação psicológica e social própria, sublinhando que um meio está em contínuo diálogo com os padrões (sociais e cognitivos) anteriores a ele. Além disso, McLuhan entendia que toda tecnologia constrói (e faz parte de) um "ambiente de serviços" (environment services). Neste sentido, independentemente do conteúdo, quando uma tecnologia é adotada na sociedade, ela não afeta

Prof. Dr. Vinícius Andrade Pereira, na Universidade do Estado do Rio de Janeiro, ao longo do segundo semestre de 2004.

${ }^{6}$ Para aquele autor, haveria dois tipos de meios de comunicação: com características temporais (time-biased) e com características espaciais (space-biased). Conseqüentemente, diferentes formas de governo floresceriam ou pereceriam na medida em que uma ou outra mídia se colocasse como instrumento principal de comunicação (Teocracias locais ou vastos Impérios, respectivamente).

7 Para comentários sobre a obra e vida de Innis, ver introdução de Crowley \& Heyer em Innis, 1999; Briggs \& Burke, 2004.

8 As noções de meios (tecnologias) em McLuhan abarcam uma gama de artefatos e sistemas mais amplos do que os de Innis, que estava preocupado com as tecnologias da comunicação mais tradicionais. Para uma discussão dos sentidos de meio em McLuhan, ver Pereira, 2004b. 
apenas aqueles que estão diretamente expostos, mas acaba propiciando a existência de um sistema (ambiente) de tecnologias (serviços), estruturando toda a vida social ao redor9 (McLuhan, 1964; Bolter \& Grusin, 2000; Pereira, 2004b).

Baseando-se nestes referenciais para análise das características materiais dos meios de reprodução sonora, optou-se por criar categorias que permitam a sistematização do estudo. Estas categorias funcionam como ferramentas metodológicas que sublinham os pontos-chave da análise:

Reprodutibilidade Técnica: (não confundir com reprodução sonora) está ligada à possibilidade de produzir ou não a cópia do conteúdo de uma mesma matriz. A questão da reprodutibilidade, ou duplicação, do formato tem implicações no desenvolvimento da indústria fonográfica e respectivas formas de comercialização da música gravada.

Capacidade de Armazenamento: refere-se à quantidade informação armazenada num suporte.

Durabilidade: capacidade de uma mídia resistir ao tempo enquanto objeto material em si. Este item é fundamental para se pensar no tipo de investimento que configura a música gravada e na longevidade de um formato.

Padrão de Consumo: cada novo formato dialoga com o(s) anterior(es) no processo de inserção na cultura. Padrões de consumo sublinham as continuidades (como um formato absorve a cognição de seu anterior) e rupturas (se torna uma novidade em si, com sua própria linguagem) dessas tecnologias, apontando para o status cultural do formato.

Sublinha-se que tais categorias materiais não determinam o desenvolvimento dos formatos fonográficos. Entretanto, estes quatro itens são significativos, pois sintetizam importantes aspectos que norteiam a história

\footnotetext{
9 De fato, McLuhan foi um autor enfático ao sublinhar a necessidade do estudo das dinâmicas tecnológicas em si (meio), relativizando uma tradicional discussão restrita aos conteúdos (mensagem). Aqui, em ambos significados, queremos afastar a idéia que uma tecnologia causa "impactos" ou "revoluções" apenas por sua existência.
} 
dos formatos, independentemente do conteúdo gravado. Neste sentido, cabe explicar a ausência de duas categorias que, à primeira vista, seriam importantes: o custo de um formato e a qualidade da reprodução. Ainda que no discurso do mercado estas duas expressões sejam continuamente enfatizadas, um olhar mais detido demonstra que tais argumentos nem sempre são fundamentais na história da mídia fonográfica. Primeiramente, o relativo custo de um meio nem sempre é determinante na sua adoção como principal produto da indústria, pois um formato mais caro monetariamente pode ser entendido tanto pela indústria quanto pelos consumidores como um produto mais interessante e seguro para investimento. Particularmente problemático é o caso da qualidade da reprodução. Sabe-se que o surgimento das tecnologias de reprodução sonora condiciona novas formas de audição, fazendo com que o julgamento sobre "fidelidade" da gravação sonora seja relativo aos parâmetros cognitivos e sociais estabelecidos em torno de um meio em determinada época ${ }^{10}$ (Chanan, 1995; Sterne, 2003). Além disso, a chamada "qualidade" da reprodução sonora não é crucial para o sucesso ou fracasso de um formato, sendo o caso da fita cassete em relação ao LP ilustrativo.

Assim, dividiu-se o trabalho em três grandes momentos que demarcam claras mudanças na história da indústria fonográfica, e que têm em diferentes tecnologias da comunicação e da informação importantes agentes de mudança.

\footnotetext{
${ }^{10}$ Um exemplo recente é a discussão entre as qualidades do vinil em comparação ao compactdisc. Em suma, os defensores do vinil preferem a reprodução mais grave dessa mídia e creditam ao CD um som muito limpo, sem as nuanças sonoras presentes no antigo formato. Por seu turno, os ouvintes do formato de reprodução digital consideram irrelevante tal "acusação", pois as novas tecnologias permitem manipulações sonoras que compensam a suposta "perda" de qualidade. Esse debate aponta para a complexidade da idéia de qualidade de reprodução sonora. Em outras palavras, a discussão reside em diferentes parâmetros sociais e de cognição sonora organizados a cada nova tecnologia (uma organizada pelo som característico do formato em vinil, outra, pelo som do CD). Isto prova que a discussão sobre a qualidade da reprodução sonora é um caso a parte a ser estudado em que não conta apenas a questão tecnológica. Para uma história social da idéia de alta-fidelidade, ver Sterne, 2003.
} 


\section{Do Cilindro ao Disco}

Este primeiro momento começa em fins do século XIX e se estende ao limiar da Segunda Guerra Mundial. Sua complexidade e relevância estão não somente no amplo espectro temporal, mas nas diversas inovações tecnológicas que acabaram por transformar a gravação sonora em indústria de entretenimento massivo.

Em 1877, Thomas Edison recebeu a patente do fonógrafo ${ }^{11}$, aparelho que gravava e reproduzia sons, sendo mais uma tecnologia derivada da, então, recente possibilidade da reprodução sonora ${ }^{12}$ (Sterne, 2003). Ainda que considerados a mais nova "maravilha" da ciência, o fonógrafo e seus cilindros apresentavam limitações técnicas para a formação de uma indústria em termos massivos. Primeiramente, se o aparelho permitia a gravação e reprodução sonora, ele deixava escapar a possibilidade de reprodutibilidade técnica do som, pois não havia como fazer cópias das gravações: uma vez gravado, o conteúdo estava condenado a permanecer no mesmo cilindro, tornando-se uma peça única. A própria durabilidade do formato também deixava a desejar, pois o papel estanho logo se desgastava, além dos cilindros - posteriormente feitos de cera 13 - facilmente quebrarem tornando sua vida útil curta (Chanan, 1995; Dowd, 2002; Gitelman, 1999).

\footnotetext{
${ }^{11}$ A máquina consistia num cone ligado a um diafragma que, com a vibração resultante do som produzido, fazia uma agulha inscrever um sulco horizontal sobre um cilindro coberto por papel estanho (Tin-foil), tão logo o usuário girasse uma manivela que movia cilindro. A reprodução do som acontecia quando a manivela era rodada no sentido contrário. Ver Gitelman, 1999; Sterne, 2003.

12 Antes do surgimento do fonógrafo, havia algumas tecnologias que apresentavam progressos na obtenção da reprodução sonora - classificada por Jonathan Sterne como a possibilidade de transformar o som num sinal e depois convertê-lo em som novamente -, como o telefone e o fonautógrafo (phonautograph), por exemplo. A "novidade" do fonógrafo era ser o primeiro aparelho a gravar e reproduzir o som. Para uma discussão da história da reprodução sonora, ver Sterne, 2003.

${ }_{13}$ Cabe fazer uma rápida distinção na história dos aparelhos. De fato, nos primeiros fonógrafos os cilindros de papel estanho não eram removíveis. No início da década de 1880 , pesquisadores do laboratório Delta (Chichester Bell e Charles Tainter), de Alexander G. Bell, alcançaram melhoramentos naquele sistema, produzindo uma máquina que utilizava cilindros de cera removíveis e raspáveis, o Grafofone (Graphophone), comercializado concomitantemente ao fonógrafo durante o fim do século XIX. Apesar de não ter aceitado a proposta de joinventure com Bell, Edison não tardou em "copiar" os melhoramentos do
} 
Em 1888, Emile Berliner conseguiu a patente para um novo aparelho chamado Gramofone. Sua principal diferença era a utilização do formato de disco para gravação cujos sulcos eram laterais e ficavam apenas num dos lados do objeto. A novidade do formato era a descoberta de um método de duplicação dos discos, que passaram a serem feitos em goma-laca (shellac) e reproduzidos numa matriz de cobre. Retrospectivamente, isso representou a possibilidade de reprodutibilidade técnica massiva da gravação sonora (Chanan, 1995; Sterne, 2003), provocando numa importante mudança:

A solução da reprodução em massa implicou na separação do processo de gravação do de reprodução. (...) um modelo de consumo estava estabelecido, no qual tratava-se o disco como um livro e não, por exemplo, como uma fotografia. O gramofone tornou-se um instrumento de reprodução ${ }^{14}$. (Chanan, 1995; 28/29).

Esse novo "modelo" (padrão) de consumo relacionava-se à gradual especialização das funções de gravação e reprodução, resultando na venda de conteúdos em discos pré-gravados, não mais suportes para gravação doméstica. Com a invenção do disco de face dupla (com gravações nos dois lados), nas primeiras décadas do século XX, a indústria fonográfica organizouse na forma como hoje se encontra - uma indústria de entretenimento massivo para consumo individualizado e preferencialmente para o lar.

Porém, após a Primeira Guerra Mundial, com o rápido aperfeiçoamento tecnológico, o aparelho de rádio se tornou um concorrente dos gramofones como bem de consumo doméstico. Além disso, trazia “novas” tecnologias como caixas amplificadoras nos aparelhos e a utilização de microfones nos estúdios - que impuseram novas demandas para consumo da reprodução sonora, causando mudanças nos rumos da indústria fonográfica. A mais

Grafofone, tornando este aparelho apenas uma sombra na história do fonógrafo. Para mais informações, ver Dowd, 2002.

14 "the solution to the problem of mass reproduction involved the separatin of the process of recording from that of reproduction. (...). but a model of consumption was estabilshed which treated the record like a book, and not like, say, a photograph. The gramophone became an instrument for playback". 
importante seria a adoção da gravação elétrica, por volta da segunda metade da década de $1920^{15}$. Surgia, então, o formato de 78 r.p.m. (rotações por minuto), que se tornou padrão da indústria, com duração aproximada de quatro minutos em cada um de seus dois lados.

Na medida em que o setor radiofônico competia com outro ramo do entretenimento, o cinema, ele passou a investir no controle de "matériaprima”, especialmente as gravações musicais e os direitos que lhe cabiam. Assim, as grandes empresas de rádio-difusão norte-americanas (RCA, CBS, NBC) passaram a comprar as companhias de discos que, incapacitadas pela crescente competição tecnológica, tornaram-se subdivisões daquele setor (Chanan, 1995). Com as junções, as novas indústrias apostariam em pesquisas de materiais e processos de gravação que possibilitassem ampliar os lucros. Porém, formatos mais "satisfatórios" somente seriam adotados após a Segunda Grande Guerra.

\section{5 r.p.m., Fita Magnética e o Long-Play}

Como conseqüência direta da Segunda Guerra Mundial, buscaram-se novas matérias-primas para os discos, uma vez que o exército japonês cortara o suprimento, para os EUA e Europa, de goma-laca produzida na Ásia. Experiências com plásticos térmicos resultaram na escolha do vinil como o material mais apropriado. Além disso, a descoberta do processo de gravação em microssulco (microgroove) possibilitaria diminuir o tamanho dos entalhes na superfície dos discos ao mesmo tempo em que aumentava a freqüência

\footnotetext{
${ }_{15}$ A eletrificação de discos e aparelhos reprodutores representou uma importante guinada tecnológica na indústria fonográfica. Por um lado, a eletrificação prometia uma "qualidade sonora melhor" ao consumidor. No entanto, sua contribuição à fonografia e à música foi inestimável. Neste caso, surgiram diversos artistas especializados em técnicas de estúdio que melhor se adequavam aos novos equipamentos de gravação. Naquele, a eletrificação significou o início de uma relação mais próxima entre setores da comunicação, dando início à competição tecnológica. O primeiro aparelho a concorrer com o rádio foi o Orthophonic Victrola, lançado nos EUA em 1924, pela Victor Talking Machine (Sterne, 2003). Com ele surgia, pode-se dizer, a "angústia dos aparelhos de reprodução", ou seja, os aparelhos reprodutores sempre se modificam a fim de propiciar a "melhor" experiência sônica mediada, em geral para concorrer com outros setores da comunicação.
} 
sonora registrada. Essas inovações resultariam no surgimento de uma nova geração de mídia, o 45 r.p.m., a fita magnética e o Long-Play.

A história do disco de 45 r.p.m. possibilita-nos fazer uma ponte com o período anterior. No pós-guerra, a televisão se tornara o investimento da vez e, como acontecera com o rádio, promovia uma reorganização do mercado de comunicação e entretenimento. A RCA-Victor ${ }^{16}$ procurou investir em pesquisas num aparelho que unisse rádio, vitrola e televisão. Portanto, a missão da divisão fonográfica era buscar um disco menor e mais leve do que o de 78 rotações, que pudesse ser facilmente trocado nos recarregadores automáticos da futura máquina (Magou, 2002). Neste caso, o vinil e o microssulco foram utilizados para comprimir a informação armazenada na mídia17 ${ }^{17}$ Dessa forma, o meio daria continuidade ao anterior, com uma música em cada lado do disco, pois o objetivo era transformar rapidamente o 45 r.p.m. no padrão do mercado fonográfico (Magou, 2002).

No entanto, durante a fase de pesquisas, dois outros formatos colocaram em xeque as perspectivas de “inovações”. O primeiro era uma nova versão do 78 rotações, surgida em 1947, com tecnologia que permitia a gravação de freqüências sonoras mais amplas (fruto de pesquisas militares com radar na IIGM). O segundo era o Long-Play, lançado no mercado em meados de 1948, apresentando um aumento da capacidade de armazenamento de informação em cada lado do disco. Mesmo enfrentando esse novo contexto, o 45 r.p.m. foi comercializado em 1949, pois se acreditava que a força da marca Victor e a junção com a televisão seriam suficientes para garantir o sucesso (Magou, 2002).

O lançamento do produto não correspondeu às expectativas. Primeiramente, o imaginado aparelho que conjugaria todos os eletrosdomésticos sequer saiu do projeto (Magou, 2002). Além disso, as revistas

${ }^{16}$ Surgida em 1929, com a compra da Victor Talking Machine pela Radio Corporation of America (RCA), ela era, no pós-guerra, a única grande empresa fonográfica a produzir tanto aparelhos reprodutores (hardware) quanto discos (software) (Magou, 2002).

17 Tal estratégia parecia se basear na experiência mal sucedida da empresa do lançamento de um disco com mais capacidade de armazenamento informacional, em 1931 (Chanan, 1995). 
especializadas em música questionaram a validade do formato, visto como uma "resposta retrógrada" ao long-play (Keightley, 2004). Tal comparação é interessante, pois se não é possível afirmar que o 45 r.p.m. tenha sido um fracasso ${ }^{18}$, a analogia refletia os novos padrões de consumo instaurados pelo formato long-play ${ }^{19}$.

Enquanto isso, uma "velha" tecnologia da comunicação ganhava renovado interesse no período de Guerra: a gravação magnética ${ }^{20}$. Com os novos microssulco e LP permitindo um aumento na quantidade de informação, havia a necessidade de um novo suporte para a gravação em estúdio, mais prático do que os velhos sistemas em 78 rotações em acetato. Não apenas as fitas magnéticas eram o suporte adequado às inovações tecnológicas como também eram maleáveis, podendo ser cortadas e editadas, criando novas técnicas de manipulação sonora no estúdio (Chanan, 1995; Millard, 2002).

Com este meio, a reprodutibilidade técnica do conteúdo tomaria novas significações. Pois as fitas magnéticas representaram o retorno da possibilidade de gravações sonoras não-profissionais, o que acabaria provando ser de grande impacto para a cultura fonográfica. Em primeiro lugar, porque possibilitou o surgimento de diversas estéticas musicais, baseadas nas experiências de gravação e produção domésticas (Chanan, 1995; Millard, 2002). Além disso, com lançamento da fita cassete em 1963, surgiram

\footnotetext{
${ }^{18}$ Com efeito, o 45 r.p.m., ou compacto (single), tornou-se um meio central para o surgimento do rock n' roll e outros estilos musicais "marginais", pois fora dotado com formato principal da indústria independente norte-americana.

${ }_{19}$ Se a comparação fosse com o tradicional 78 rotações (seu formato físico, sua forma de recepção), o single apresentaria significativas vantagens. No entanto, o novo contexto era prejudicial ao 45 r.p.m., pois tecnologicamente este não oferecia melhorias, além do fato da capacidade de armazenamento do LP possibilitar novas experiências de consumo sonoro. 20 A história da gravação magnética começa em 1898, quando o dinamarquês Valdemar Poulsen inventou um gravador magnético utilizando fios como suporte, o "telegrafone", hoje considerado o precursor dos gravadores magnéticos. Subseqüentes pesquisas nos anos de 1920 na Alemanha, Inglaterra e EUA levariam à adoção da fita magnética. Particularmente na Alemanha, o desenvolvimento dessa tecnologia foi notável. No entanto, com a derrota na Segunda Guerra, empresas norte-americanas tomaram as patentes das alemãs, como parte dos espólios, e deram novo impulso para o comércio da gravação magnética com fitas (Chanan, 1995; Clark, 1999).
} 
novas possibilidades de comércio e consumo de gravações sonoras. A portabilidade e a praticidade da fita cassete promoveram não apenas o incremento da pirataria - cópia e comercialização ilegal de material gravado e protegido intelectualmente - como a possibilidade do consumo móvel de gravações, especialmente com o surgimento do Walkman - o consumo de gravações sonoras ultrapassava os domínios do lar (Millard, 2002; Bull, 2001).

No entanto, o Long-Play acabou sendo a "grande inovação” do período. Lançado pela gravadora Columbia em 1948, era um disco com rotação por minuto mais demorada (33 1/3), o que permitia aumentar a capacidade de armazenamento da informação na superfície do vinil. Em pouco tempo, o formato adquiriu status de principal produto da indústria fonográfica internacional - como as reações negativas ao 45 r.p.m. sugerem. Historiadores do formato afirmam que tal sucesso se deveu ao fato de ser associado à "boa música” pelo público adulto²1 (Keightley 2004). Porém, o argumento não explica se sustenta, pois a estratégia de transferência de legitimidade cultural do conteúdo (música) para o meio (disco) era uma prática comum há muito na indústria fonográfica ${ }^{22}$. Um olhar mais atento aponta para a leitura da característica material como elemento central para a percepção do suporte. Em poucas palavras, o LP foi entendido como uma “revolução" do consumo fonográfico. Começando pelo nome dado à

${ }_{21}$ "O estabelecimento do LP como o coração da indústria norte-americana de discos também significou que, em termos econômicos, adultos se tornassem o público alvo do consumo de sons gravados. Os gêneros constantemente gravados no formato (erudito e operístico, musicais da Broadway e o jazz, etc.), contribuiu para um crescente prestígio do formato dos álbuns de música popular adulta” (Keightley, 2004, 380). No entanto, a visão do autor parece não separar discurso do mercado das mudanças efetivas que o LP trazia à indústria.

${ }^{22}$ Chanan (1995) apropriadamente observa que a gravação de música erudita sempre visou dar status cultural às gravações sonoras. Desde o século XIX, selos de qualidade foram estabelecidos para diferenciar os discos de música erudita dos de popular, sendo aqueles os principais produtos do catálogo. Com efeito, a música erudita seria um "carro-chefe" para indústria fonográfica, pois lhe daria legitimidade cultural, ainda que sua parcela nas vendas de disco sempre tenha sido menor do que as músicas populares. Além disso, também se pode argumentar que o meio transfere legitimidade ao conteúdo. O Rock n' Roll adquiriu status de "arte" quando passou a ser uma música de álbuns e não apenas de compactos (singles), o caso dos Beatles é exemplar. 
tecnologia: Long-Play - literalmente, "longa duração" -, evitando a associação com a denominação técnica da rotação por minuto ao mesmo tempo sugerindo uma nova experiência de consumo sonoro, temporalmente “alongada" em relação aos formatos anteriores. Quando, na década de 1960, os discos começaram a utilizar tecnologia estéreo (Frith, 1981), tal percepção foi "autenticada" pela tecnologia, contribuindo decisivamente para sua imagem de nova experiência de mediação sonora ${ }^{23}$. O padrão de consumo do LP também merece menção. Com o surgimento da estética do álbum, os discos passam a serem vistos como obras de arte em si. Com os trabalhos de design dos discos, durabilidade do formato - o vinil é mais resistente do que a goma-laca - e a promessa de alta-fidelidade do sistema estéreo, o LP passa a ser consumido como livros, ou seja, um suporte fechado passível de coleção em discotecas privadas - com status de objeto cultural, afinal, julga-se a cultura musical de uma pessoa pela discoteca que possui.

Com essas mídias, estabeleciam-se as estruturas da indústria fonográfica internacional no pós-guerra, considerada sua "época de ouro". Cada novo formato possibilitava ampliar não apenas os produtos como também o público consumidor de tecnologia (adultos, adolescentes, minorias raciais, classes menos abastadas, etc). No entanto, tal configuração seria obrigada a mudar com o surgimento de um novo complexo tecnológico.

\section{Tecnologias Digitais}

Dentro de um planejamento de reestruturação empresarial, a indústria fonográfica iniciou um processo que resultaria na terceirização da produção e na adoção da tecnologia digital (Dias, 2000). Em 1983, lançou-se o compactdisc, suporte digital de reprodução, feito em alumínio, menor e mais leve que um 45 r.p.m. e com a capacidade para comportar aproximadamente setenta

\footnotetext{
23 Neste sentido, é importante levar em consideração as propagandas nas capas dos discos, especialmente da década de 1960 para frente. Chamadas como "gravação estéreo", "altafidelidade" e mais recentemente "re-mixado" e "re-masterizado" servem para sugerir experiências de fruição sonora contidos nos formatos. Para além das efetivas mudanças tecnológicas, elas ajudam a construir socialmente a imagem de "nova" na tecnologia.
} 
minutos de música, sobre a mesma superfície. Ainda que o novo suporte prescindisse da "troca de lado" dos discos, o padrão de consumo do CD seguiria as regras do LP.

No entanto, o contínuo desenvolvimento da micro-informática acabou colocando problemas para a indústria fonográfica. Na década de 1990, surgiram arquivos digitais para facilitar a troca de informações pelas tecnologias em rede. Surge o Motion Picture Expert Group-Layer 3, ou MP3, como um arquivo compacto (1/12 do formato WAV do CD) para transferência de dados. Este formato era direcionado principalmente à mobilidade da informação; não ao consumo fechado num suporte material. No entanto, em 1999, quando a RRIA ${ }^{24}$ processou a empresa Napster Inc. na justiça norteamericana alegando lesão contributória e vicária de propriedade intelectual, tornou-se público uma nova prática relacionada ao consumo sonoro e às novas tecnologias da comunicação ${ }^{25}$.

Ainda que as discussões sobre a legalidade da troca de arquivos pela rede sejam relevantes, uma questão importante sobre softwares como o do Napster ou os protocolos de Par-a-Par (Peer-to-Peer) é que eles representam interessantes mudanças no comércio de música (Alexander, 2002; Jones, 2002; Martins, 2003). Por um lado, essas tecnologias demonstraram a viabilidade de um comércio virtual, criando um processo re-intermediação dos agentes da indústria fonográfica (Jones, 2002). Em outras palavras, na medida em as tecnologias em rede ampliam as possibilidades de consumo de informação sonora - com a virtualização dos suportes - e o comércio on-line

\footnotetext{
24 Recording Industry Association of America, representante das grandes empresas fonográficas nos EUA.

25 De fato, o tipo de troca efetuado pelo Napster (consumir música sem comprar o disco) não era uma novidade, pois desde a popularização da fita cassete, o comércio alternativo já se tornara uma prática comum entre os fãs de música. No entanto, o Naspter foi transformado numa "empresa" tangível pela legislação dos direitos autorais. Parte da discussão de Martins (2003) aponta exatamente para o processo e as conseqüências da construção social do Napster enquanto empresa e não comunidade virtual baseada na troca de informações entre afins. Para uma discussão da questão da pirataria, ver Alexander, 2002. Para uma discussão sobre o desenvolvimento da comunicação medida por computador a partir do caso Napster, ver Martins, 2003
} 
cresce em importância social e econômica, tradicionais mediadores do consumo musical, como o suporte físico do disco ou as lojas revendedoras, são re-mediados (Bolter \& Grusin, 2000) por empresas terceirizadas que vendem serviços e produtos associados à gravação sonora (De Marchi, 2004; Power \& Jansson, 2003).

Com os formatos virtuais - que não se restringem ao $\mathrm{MP}_{3}$ - o próprio padrão de consumo se altera. Ao invés de se restringir a um objeto em si, surge um consumo diretamente on-line, transformando a gravação sonora numa informação transferível de suportes (do CD para um HD, para o I Pod, para $\mathrm{CD}$, por exemplo). Isso significa que o formato fonográfico físico tornouse uma tecnologia para armazenamento da informação, não mais um símbolo cultural em si, como o LP. Mais do que isso, com a convergência tecnológica, o consumo sonoro se expande por diversas meios de comunicação, abrindo o mercado fonográfico a outros setores industrias - empresas de telefonia, por exemplo (Jones, 2002; Jenkins, 2004; De Marchi, 2004). Mesmo formatos "herdeiros" da linguagem do álbum, como tem se apostado com o DVD para música, participam dessa outra lógica de consumo.

Em suma, tais mudanças não significam que a indústria fonográfica esteja “em crise" - no sentido de estar acabando. Mais uma vez, ela está se reorganizando frente a novos contextos econômicos e tecnológicos. O ponto central dos formatos digitais é, de fato, a percepção de que as pessoas não consomem mais “como antigamente". As características materiais dos suportes sonoros imprimem novas dinâmicas à cultura fonográfica contemporânea.

\section{Conclusão}

À primeira vista, a compra de velhos conteúdos em novas tecnologias parece ser apenas a plena realização do consumo de conteúdos repetidos, alardeado no texto da Industrial Cultural (Adorno \& Horkheimer, 2002). 
Porém, como demonstrado, a angústia do formato é um tema complexo e central para o entendimento da dinâmica cultural relacionada à fonografia.

O objetivo deste texto foi esboçar uma visão geral do desenvolvimento da indústria fonográfica, historiando os suportes sonoros. Evitando expor minúcias técnicas, a intenção foi entender como a materialidade do formato fonográfico afeta sua significação social. Neste sentido, a utilização do referencial teórico da Escola de Toronto visou sublinhar as características materiais das tecnologias, relativizando as costumeiras discussões sobre conteúdos ${ }^{26}$. Longe de um determinismo tecnológico, demonstrou-se que a análise destes objetos permite discutir desenvolvimentos tecnológicos, mudanças industriais, hábitos de consumo de conteúdos e de mídia. Enfim, a angústia do formato nos lembra como é valorizada estética, econômica e afetivamente a mediação sonora em nossa cultura.

\section{Bibliografia}

ADORNO, Theodor W. \& HORKHEIMER, Max - Indústria Cultural: o Iluminismo como Mistificação das Massas. Em: Almeida, Jorge M.B., “Indústria Cultural e Sociedade". Paz e Terra, 2002.

ALEXANDER, Peter J. - Peer-to-Peer File Sharing: the Case of the Music Recording Industry. In: Review of Industrial Organization, 20, 151-161.

March, 2002.

BOLTER, J.David \& GRUSIN, Richard - Remediation: Understanding New Media. Massachusetts \& Londres. MIT Press, 2000.

BULL, Michael - The World According To Sound: Investigating the World of Walkman Users. In: New Media \& Society, pages 179-197. London, Thousand Oaks \& New Delhi. Sage Publications, 2001.

CHANAN, Michael - Repeated Takes: a Short History of Recording and its Effects on Music. London \& New York. Verso, 1995.

${ }^{26}$ Como a música é o principal conteúdo dos suportes sonoros, torna-se demasiado comum a discussão sobre o valor estético de movimentos musicais ou artistas, menosprezando-se a questão comunicacional da indústria fonográfica. 
CLARK, Mark H. - Making Magnetic Recording Commercial: 1920 - 1955.

In: Journal of Magnetism and Magnetic Materials 193, 8-10. 1999.

DAPIEVE, Arthur - A Angústia do Formato: Não é Nada Disso que Vocês

Estão Pensando. In: Segundo Caderno do Jornal O Globo, o8 de outubro de 2004.

DE MARCHI, Leonardo - A Nova Produção Independente: Mercado

Fonográfico e as Novas Tecnologias da Comunicação. Texto apresentado no

NPo8 (tecnologias da Informação e da Comunicação) da Intercom 2004.

DIAS, Márcia Tosta - Os Donos da Voz: Indústria Fonográfica Brasileira e

Mundialização da Cultura. São Paulo. Boitempo Editorial, 2000.

DOWD, Timothy J. - Culture and Commodification: Technology and

Structural Power in the Early U.S. Recording Industry. In: The International Journal of Sociology and Social Policy, 22, 106-140. 2002.

FRITH, Simon - Sound Effects: Youth, Leisure and the Politics of Rock n' Roll. New York. Pantheon Books, 1981.

GITELMAN, Lisa - Scripts, Grooves and Writting Machines: Representing Technology in the Edison Era. Standford. Standford University Press, 1999. INNIS, Harold A. - The Bias of Communication. Toronto. University of Toronto Press, 1999 ( $11^{\text {a }}$ edição).

JENKINS, Henry - The Cultural Logic of Media Convergence. In:

International Journal of Cultural Studies, pages 33-43. London, Thousends Oaks \& New Delhi. Sage Publications, 2004.

JONES, Steve - Music and the Internet. In: Popular Music, vol 19/2. United Kingdom. Cambridge University Press, 2000.

KEIGHTLEY, Keir - Long Play: Adult-Oriented Popular Music and the Temporal Logics of the Post-War Sound Recording Industry in the U.S.A. In: Media, Culture \& Society, vol. 26, 375-391. London, Thousand Oaks, New Delhi. 2004.

MAGOU, Alexander B. - The Origins of the 45-RPM Record at RCA Victor, 1939-1948. In: Braun, Hans-Joachim: Music and Technology in the Twentieth 
Century. Baltimore \& London, 148-157. The Johns Hopkins University Press, 2002.

MARTINS, João - Troca de Arquivos Par-a-Par: Napster, Gnutella e o Desenvolvimento de Comunicação na Internet. Tese de mestrado do Programa de Pós-Graduação em Comunicação da Universidade Federal Fluminense. Niterói, 2003.

McLUHAN, Marshall - Understanding Media - the Extensions of Man. Chicago. Signet

Books, 1964.

MILLARD, André - Tape Recording and Music Making. In: Braun, HansJoachim: Music and Technology in the Twentieth Century. Baltimore \& London, 158-167. The Johns Hopkins University Press, 2002.

PEREIRA, Vinícius Andrade (a) - Tendências das Tecnologias de Comunicação da Fala às Mídias Digitais. Em: Sá, Simone Pereira de \& Enne, Ana Lúcia: "Prazeres Digitais: Computadores, Entretenimento e Sociabilidade”, 131-146. Rio de Janeiro. E-Papers, 2004. (b) - As Tecnologias de Comunicação como Gramáticas: Meio, Conteúdo e Mensagem na Obra de Marshall McLuhan. Texto apresentado no NP o8 (Tecnologias da Informação e da Comunicação) da Intercom, 2004.

POWER, Dominic \& JANSSON, Johan - The Emergence of a Post-Industrial Music Economy? Music and ICT Synergies in Stockholm, Sweden. Disponível em www.sciencedirect.com . 2003.

SÁ, Simone Pereira de - Por uma Genealogia da Noção de Materialidade da Comunicação. Texto apresentado no NP o8 (Tecnologias da Informação e da Comunicação) da Intercom, 2004.

SINGER, Ben - Modernidade, Hiperestímulo e o Início do Sensacionalismo Popular. In: Charney \& Schwartz (org.): “O Cinema e a Invenção da Vida Moderna”. São Paulo, Coseac \& Naify, 2001. 
STERNE, Jonathan - The Audible Past: Cultural Origins of Sound

Reproduction. Durham \& London. Duke University Press, 2003. 